\title{
PROPERTY RIGHTS, INSTITUTIONS AND CHOICE OF FUELWOOD SOURCE IN RURAL ETHIOPIA
}

\author{
Abebe D. Beyene ${ }^{1}$ and Steven F. Koch ${ }^{2}$
}

\begin{abstract}
This study examines the relationship between property rights, defined by land tenure security and the strength of local-level institutions, and household's preferences for fuelwood source. A multinomial regression model applied to survey data collected in rural Ethiopia underpins the analysis. Results from the discrete choice model indicate that active local-level institutions increase household dependency on open access forests, while land security reduces open access forest dependence. However, local level institutions are found to reduce the role of private fuelwood, while tenure security has not, at least yet, had any impact on private fuelwood collection activities. The results suggest that there is a need to bring more open access forests under the management of the community and increase the quality of community forestry management in order to realize improvements in forest conservation.
\end{abstract}

JEL: Q15, Q23, O17

Key words: property rights, institutions, fuelwood, rural Ethiopia.

\section{INTRODUCTION}

Like residents of many developing countries, Ethiopians depend heavily on biomass resources such as fuelwood, dung and agricultural crop residues. According to the Central Statistical Agency (CSA, 2012), over 95\% of the country's total energy for household cooking is derived from biomass fuels $-85 \%$ from firewood, around $4 \%$ from charcoal and more than $7 \%$ from leaves and dung. The rural population is even more dependent. At least $99 \%$ of the rural population uses wood and other traditional biomass resources, such as animal dung, leaves and residues (CSA, 2012), while Mamo et al. (2006) find that forest resources contributed, on average, $39 \%$ of household income. The heavy reliance on biomass energy sources has resulted in serious forest degradation. Between 1990 and 2010, the Food

\footnotetext{
${ }^{1}$ Department of Economics, University of Pretoria, Private Bag X20, Hatfield 0028, South Africa, abebed2002@yahoo.co.uk.

${ }^{2}$ Professor and Head, Department of Economics, University of Pretoria, Private Bag X20, Hatfield 0028, South Africa, steve.koch@up.ac.za, +27(12) 420-5285.
} 
and Agriculture Organization of the United Nations (FAO) estimates, Ethiopia lost an average of 141,000 ha $-0.97 \%$ of the remaining forest area- each year (FAO, 2010). Fuelwood collection, together with land clearing for agriculture, overgrazing and other shocks (such as fires) also contribute to the unsustainable use and misuse of forests in Ethiopia.

Given that all major forests in Ethiopia are state-owned, while the government, like those in many other low-income countries, has neither the capacity nor the incentive to properly regulate these forests, such rates of forest degradation may not be that surprising. Mekonnen and Bluffstone (2007) note that the regulation incentive is particularly low in Ethiopia, because forests produce goods used mainly by local villagers. State ownership combined with limited regulation leads to de facto open access to all forests, which, due to the tragedy of the commons (Hardin, 1968), is expected to aggravate the degradation and deforestation problems in the country. Fortunately, the problem has been recognized and there is keen interest within government to alleviate or reverse the situation, as evidenced by the recent approval of the Ministry of Agriculture and Rural Development's Forest Development, Conservation and Utilization Policy and Strategy (MoARD, 2007).

Some of the objectives of MoARD (2007) include: (i) increasing the contribution of forests to the economic development of the country, (ii) maintaining ecological balance, and (iii) conserving and enhancing biodiversity, through the sustainable utilization and development of forest resources. To achieve these objectives, MoARD (2007) supports the provision of tree seedlings to farmers, as well as the continued extension of land tenure security. This latter policy component was modelled on an effort in Tigrai during the late 1990s. The initial 1990s program on land certification was extended to the country's main regions in 2003, with 
the objective of reducing tenure insecurity and its negative impact on land investment (Deininger et al., 2008). The success of these policies, however, hinges on the behavioural response of households to changes in tenure security, which is likely to depend upon their perceptions of a variety of institutional features.

There are three major issues within the literature that are relevant to this study. The first of these is the effectiveness of improved tenure security on agricultural investments; a positive relationship implies improved fuelwood availability, and, thus, the potential for changes in the choice of fuelwood collection source. Deininger et al. (2009), for example, find that, despite policy constraints, a low-cost land registration program in Ethiopia has resulted in increased soil and water related investment. Holden et al. (2009) provide further evidence; land certification has led to improved maintenance of soil conservation structures, increased investment in trees, and increased land productivity. Mekonnen (2009) finds that land tenure insecurity influences the decision to grow trees, but not the number of trees grown; however, Mekonnen used perceived expropriation of land in the five-year period after the survey as an indicator of land tenure insecurity, rather than actual certification, which we are able to use.

The second of these is the relationship between fuelwood source choice and property rights regimes in developing countries. Jumbe and Angelsen (2011), who consider Malawi, find a high correlation between the specific attributes of fuelwood collection sources (such as area, species, and distance to the forest) and the household's choice of fuelwood collection source. Among the three types of fuelwood sources in their study: customary forests, plantation forests, and forest reserves, customary forests and forest reserves are substitutes, while substitution is more limited between plantation forests and forest reserves. However, Jumbe and Angelsen (2011) do not examine the role of either private sources or markets, which we are 
able to include in this study. Linde-Rahr's (2003) Vietnamese study, which is similar to Jumbe and Angelsen (2011), finds strong substitution between open access and private plantation forests. Unfortunately, only a few researchers have examined the role of private trees. Heltberg et al. (2000) find evidence of substitution between forest fuelwood and private energy sources (like dung, residues and homestead trees) in India. Similarly, Cooke et al. (2008) indicate that private trees and trees in common forests are fuelwood production substitutes for rural households in Ethiopia, India, and Nepal, at least for households owning land. With respect to Ethiopia, Mekonnen (1999), one of the first empirical studies of fuelwood substitution, cautions that the consumption of other biomass energy, such as dung and crop residues, is not likely to decrease, when more fuelwood is available, meaning that there is minimal substitution across fuelwood collection activities. In our analysis, we focus more explicitly on the multifaceted choice sets that face fuelwood consumers and producers, rather than the actual amount of production and consumption. Furthermore, we tie those choices to differences in land tenure and forestry institutions, which could not form part of Mekonnen's (1999) analysis. However, unlike Mekonnen, we do not examine actual levels of production, collection or consumption, which we hope to consider in future research.

The third of these is the examination of detailed common property design elements, or common property forestry institutions, that are well established in the literature (Ostrom, 1990; Agrawal 2000; 2001; Agrawal et al, 2008). Using different measures of institutional elements, we are able to explicitly incorporate institutional roles and their effects on the choice of fuelwood source, extending Agrawal et al. (2008), Bluffstone et al. (2008) and Mekonnen and Bluffstone (2008). Ostrom (1990) and Agrawal (2000, 2001) find evidence that local level institutional elements, such as: clear access and extraction rules, fair and graduated sanctions, public participation, clear quotas and successful monitoring, contribute 
to better natural resource management. However, to our knowledge, the indirect relationship, from stronger institutions to rural household fuelwood production behaviour, through better natural resource management, has not been considered. Hence, our study contributes to the literature by providing better information on the role of some of the specific elements of local institutions on household fuelwood collection decisions, when facing different forest property right regimes.

As outlined above, the available empirical literature focuses on rural energy consumption and production, is geographically limited, and does not emphasize either local-level institutions or tenure security on forestry resource use. Although the initial MoARD program has received some attention in the literature, that focus has been on the investment effects of the land certification policy. To our knowledge, no study has considered the possible impacts of the program on forestry use. Therefore, the purpose of this study is to add to the empirical literature by considering the determinants of the household's fuelwood source choice. Although household level variables are assumed to influence that choice, this analysis focuses on tenure security and local level institutions related to community forestry management to determine whether these policies and institutions are associated with any differences in collection activities at the household level. Our multinomial logit estimates indicate that active local-level institutions increase the probability of collection from open access areas, but reduce collection from private sources. However, although tenure security does reduce the demand for open access fuel wood, tenure security does not impact household decisions to collect fuel wood from private sources. Similarly, the analysis provides some insight related to substitution patterns between fuelwood collection sources. Based on the findings of the study we provide policy implications related to the management and conservation of forests. 
The remainder of the paper is organized in the usual fashion. Section 2 outlines the analytical framework, including the theoretical motivation and empirical methodology. The theoretical model examines cost minimization, rather than utility maximization, as is common in the literature. The empirical methodology, on the other hand, is based on an intuitive variant of the random utility model and its estimation, via multinomial logit. The data and study areas are described in Section 3. Empirical results and a discussion of these results are provided in Section 4, while Section 5 presents concluding remarks.

\section{ANALYTICAL FRAMEWORK}

\subsection{Theoretical motivation}

Consider a household requiring a predetermined amount of fuelwood for heating, cooking and lighting; we abstract from the underlying problem of determining the demand for energy at the household level, to keep the problem manageable. The household is assumed to be able to satisfy their fuelwood requirements from a variety of sources, $s=\{$ private $(p)$, community (c), market (m), open access (o) or numerous sources (n)\}, and is further assumed to minimize the cost of satisfying that need, subject to a number of constraints, including fuelwood collection/production constraints that are assumed to be source-specific, input constraints that are assumed to be determined by available resources, and various nonnegativity constraints. In terms of notation, $F_{S}\left(X_{S}\right)$ represents the production (or purchase) function for source $s$ using inputs $X$, which is assumed to depend on the available technology and institutions, $w_{s j}$ represents the wage of input $j$ associated with source $s, x_{s j}$ represents input $j$ used in source $s, \bar{F}$ represents the fuelwood requirement for the household, $m$ is the market price of fuelwood, $F_{m}$ is the amount purchased from the market, and $\bar{X}_{j}$ is the availability of input $j$ for the household. Unfortunately, the available data does not include 
any directly observable prices, and therefore, other measures must be used, instead, as proxies; these will be described below.

Given the preceding notation, the household's minimization problem is outlined in (1).

$$
\min _{X, F_{m}}\left[\left(\sum_{s} \sum_{j} w_{s j} x_{s j}\right)+m F_{m}\right]+\lambda\left[\bar{F}-\sum_{s} \eta_{s} F_{s}\left(X_{s}\right)\right]+\sum_{j} \theta_{j}\left[\bar{X}_{j}-\sum_{s} x_{s j}\right]
$$

The first term in equation (1) is the cost of producing, collecting or purchasing fuelwood; the second term requires the total collection/purchase to meet the fuelwood requirement, with constraint multiplier $\lambda$, but also includes the fact that collection/purchase must be nonnegative from all sources, with separate constraints for each source, $\eta_{s}$; the third term requires input usage to not exceed input availability, and there are separate multipliers, $\theta_{j}$, for each input. Despite the simplification, abstracting from the household's optimal energy requirements, there are a number of remaining complexities. The solution, for example, yields a variety of input demands across each of the different fuelwood choices, and these demands could be zero for any particular fuelwood choice. There are two typical first order conditions for input choices: one for any input associated with fuelwood purchase, $x_{m j}$, and another for any input used for collecting or producing fuelwood, $x_{s j}$, rather than purchasing. In addition to the input choice conditions, there are a number of constraint conditions. 


$$
\begin{gathered}
x_{m j} \rightarrow x_{m j}\left[w_{m j}+m F_{m j}-\lambda \eta_{m} F_{m j}-\theta_{j}\right]=0 \\
x_{s j} \rightarrow x_{s j}\left[w_{s j}-\lambda \eta_{s} F_{s j}-\theta_{j}\right]=0, s \neq m \\
\lambda \rightarrow \lambda\left[\bar{F}-\sum_{s} \eta_{s} F_{s}\left(X_{s}\right)\right]=0 \\
\eta_{s} \rightarrow \eta_{s}\left[F_{s}\left(X_{s}\right)\right]=0 \\
\theta_{j} \rightarrow \theta_{j}\left[\bar{X}_{j}-\sum_{s} x_{s j}\right]=0
\end{gathered}
$$

The conditions in equation (2) follow two conventions. The first is the Kuhn-Tucker convention that either the term in square brackets is zero, or the pre-multiplied choice variable is zero. The second is that the subscripts on the functions represent the derivative of the collection, production or purchase source with respect to the input considered.

To illustrate the possible solutions, let us consider two different households. The first is assumed to only purchase fuelwood, while the second chooses to collect fuelwood from two different sources; all other solutions can be shown to have similar solution structures. If a household chooses only to purchase fuelwood, $F_{s}=x_{s j}=0$, when $s \neq m$, while $\bar{F}=F_{m}$. Finally, $x_{m j}=\bar{X}_{j}>0$, yielding $w_{m j}+m F_{m j}-\lambda \eta_{m} F_{m j}-\theta_{j}=0$. Importantly, for $x_{s j}=0$, $w_{s j}-\lambda \eta_{s} F_{s j}-\theta_{j}>0$, implying that the opportunity cost of input $j$ in the collection or production of fuelwood is too high, a result that arises from a wage that is too high, a sourcespecific input productivity that is too low, or an input availability that is too limited. In the case where a household chooses to make use of two different sources, but does not purchase fuelwood, $x_{m j}=0$, such that $w_{m j}+m F_{m j}-\lambda \eta_{m} F_{m j}-\theta_{j}>0$, implying the opportunity cost of the input associated with fuelwood purchase is too high to justify purchase, e.g., the price of fuelwood is too high, or the productivity of the input associated with fuelwood purchase is better used in other activities. Similarly, for $x_{s j}>0$, the bracketed term 
associated with the input vanishes, $w_{s j}-\lambda \eta_{s} F_{s j}-\theta_{j}=0$, and the sum of collection or production activities from all of the sources used yields the required fuelwood for the household.

Although these conditions are important for understanding the driving forces behind fuelwood source choice, the focus of this research is on the influence of land security and community forestry institutions on these choices. Assuming that land is an important input to the private production of fuelwood, the effect of land security is subsumed within the land input constraint; increases in tenure security are expected to increase available land for fuelwood production, relax the land constraint and reduce the relative cost of collecting fuelwood from private sources. With respect to community forestry institutions, the effects are likely to differ across households. For households with access to community forests, better institutions are expected to increase the productivity of the inputs used in community forest fuelwood extraction; however, for households without access to community forests, better institutions are expected to increase the opportunity cost of using community forests for fuelwood collection through, for example, the imposition of fines on inappropriate use of the community forest. In the first instance, better institutions should increase the likelihood of using the community forest over other sources; the intuition is reversed in the second instance.

\subsection{Empirical methodology}

The preceding theoretical framework results in a minimized cost of collecting, producing and/or purchasing fuelwood to meet the households' requirements. For the majority of the households in our dataset, fuelwood is collected, produced or purchased from a single source, such that an appropriate empirical methodology for analysing fuelwood source choice is a 
random cost model, a variant of the random utility model (e.g., McFadden, 1973, 1974; Train, 1998; and Ben-Akiva et al., 1993). In our approach, every household has a cost function, which allows for the ranking of alternatives in a consistent and unambiguous manner, but that cost is not completely observed by the analyst, requiring the inclusion of an unobserved component. Given the further assumption of cost minimization, the household's choice is, thus, their lowest cost alternative.

As in the theoretical model, consider a household choosing between five different possible sources of fuelwood for their energy needs: private (or own sources), community forests, the market, open access forests, or multiple sources. Households are assumed to select the fuel source option that minimizes their expected cost, and, therefore, the household chooses a fuel source based on factors associated with their options. For the $i^{\text {th }}$ household faced with $s$ choices, the cost of choice $s \in\{p, c, m, o, n\}$ can be written as (e.g., McFadden, 1973, 1974):

$$
C_{i s}=X_{i s} \beta_{s}+\varepsilon_{i s}
$$

The preceding structure of household $i$ 's cost of using option $s$ is similar to the standard random utility model, where $C_{i s}$ is the cost associated with $i$ 's choice of fuelwood source $s$, $X_{i s}$ is a vector of explanatory variables that affect the choice of fuelwood source, $\varepsilon_{i s}$ is a disturbance term and $\beta_{s}$ is the vector of parameters, coinciding with the variables that are deemed to influence the cost of choice $s$. Assuming that $s$ is the preferred fuelwood source, it can be presumed that the random cost associated with $s$ is exceeded by the random cost associated with any other $s^{\prime}$ that is not $s$.

$$
C_{i s}<C_{i s \prime}, s \neq s^{\prime}
$$

Depending on the distribution of the disturbance terms, various empirical structures can be applied. The analytical model followed here is the multinomial logit. Because of the need to 
evaluate multiple integrals of the normal distribution, the probit model has found rather limited use in this setting (Greene, 2003). The logit model, in contrast, has been widely used in empirical research, due to its relative ease of estimation. However, the one drawback of the model is the assumption used to derive its formulation, that all choices are independent of irrelevant alternatives (IIA). Violations of this assumption result in biased estimates, and, therefore, this underlying assumption was tested. Specifically, Hausman tests for IIA were considered for each of the reported multinomial logit regressions. However, the underlying condition of the test, that the variance matrix is positive semi-definite was violated.

Therefore, we proceed under the assumption that IIA is not a significant problem. The probability that $s$ is chosen is the probability that the random cost of choice $s$ is exceeded by that of all other choices $s^{\prime} \neq s$.

$$
\operatorname{Pr}\left(C_{i s}<C_{i s \prime}\right) \forall s \neq s^{\prime}
$$

Equation (5) can be further rearranged.

$$
P_{i s}=\operatorname{Pr}\left(X_{i s} \beta_{s}+\varepsilon_{i s}<X_{i s^{\prime}} \beta_{s^{\prime}}+\varepsilon_{i s^{\prime}}\right)=\operatorname{Pr}\left(\varepsilon_{i s}-\varepsilon_{i s^{\prime}} \leq X_{i s^{\prime}} \beta_{s^{\prime}}-X_{i s} \beta_{s}\right)
$$

Assuming that $\varepsilon_{i s}-\varepsilon_{i s}$, has a logistic distribution, the probability for the choice of fuelwood source can be specified as (Greene, 2003):

$$
P_{i S^{\prime}}=\frac{\exp \left(X_{i s} \beta_{s^{\prime}}\right)}{\sum_{s} \exp \left(X_{i s} \beta_{s}\right)}
$$

In (7), $X_{i s}=X_{i s \prime}$, although their means are different across the different sources (Table 2). Since, $\sum P_{i s}=1$, a restriction is needed to ensure model identification. Hence, we set $\beta_{p}=0$, so the remaining coefficients can be interpreted as being relative to private fuelwood. Due to the complex nonlinearity of the multinomial regression model, the estimated coefficients are difficult to interpret. Therefore, interpretation is based upon the marginal effects of the 
explanatory variables on the probabilities. The marginal effects measure the expected change in the choice probability with respect to a unit change in the requisite explanatory variable. Marginal effects for the $k^{\text {th }}$ variable in $X$ are derived as in Greene (2003), and will be presented at the mean for continuous variables.

$$
\delta_{j k}=\frac{\partial P_{j}}{\partial x_{k}}=P_{j}\left[\beta_{j k}-\sum_{h \neq j \in J} P_{h} \beta_{h k}\right]
$$

In the case of a binary independent variable, marginal effects are determined by the differences between the probabilities; the first probability in the difference is calculated with the binary indicator set to one, while the second probability in the difference is calculated with the binary indicator set to zero.

\section{DATA SOURCE AND DESCRIPTIVE STATSITICS}

\subsection{Nature and source of data}

The data for the analysis was collected in 2007 from a sample of rural households in the East Gojam and South Wollo zones of the Amhara region of Ethiopia. This data is part of a longitudinal survey conducted through a collaborative research project between Addis Ababa University and the University of Gothenburg, and financed by the Swedish International Development Cooperation Agency/Swedish Agency for Research Cooperation (Sida/SAREC). The selection of the sites was deliberate, and ensured variation in the characteristics of the sites, including agro-ecology and vegetative cover (Mekonnen, 2009). The sample sites were selected purposively and households from each site were then selected based on a simple random sampling technique. About 120 households from each of 14 kebeles were selected. An additional 80 households were interviewed for reasons not explicated in the survey documentation; thus, a total of 1760 households from 14 sites were 
interviewed, as part of the survey. Our study focuses on responses with complete information, especially on information related to institutional perceptions; see below.

The data includes information on household characteristics such as age, sex and education of household head, size of household, household perceptions regarding land certification and registration, energy collection and consumption, assets, credit, off-farm activities, the nature and type of forests and other information, such as: the distance to the nearest forest, the nearest town, and economic status indicators of the household (i.e., land size and livestock ownership). The theoretical model outlines a decision process that depends upon the relative costs of using a household input (land, labour or even monetary income), for the collection, production or purchase of fuelwood. For that reason, the variables included in the empirical model are meant to capture those costs, as far as possible, given certain limitations. The most limiting feature of the data is that factor costs across activities are not generally observed. Labour markets in rural Ethiopia are thin, as are land rental markets, and, therefore, a number of proxies are included in analysis to deal with this problem. The most obvious proxies include land and livestock holdings, which are included in log form, as well as distances to the nearest town and forest. Access to more land lowers the opportunity costs of privately producing fuelwood, thus reducing the attractiveness of other fuelwood sources, while livestock ownership potentially raises that opportunity cost by competing with forestry activities, increasing the attractiveness of alternative sources; however, livestock ownership and land ownership also indicate economic status, and, this, the ability to absorb costs. The distance to town provides an indication of the cost of accessing fuelwood markets, such that greater distances reduce the likelihood of purchasing fuelwood. On the other hand, decreased distance to the nearest forest would lower the relative cost of collecting or producing fuelwood from non-private sources. Although these included proxies are rather 
straightforward, the relationship between the opportunity costs in one source and the resulting substitution towards another source remains an empirical question.

In addition to the preceding variables, a number of other variables were also included, focusing primarily on labour and labour costs. For example, household size provides an indication of labour availability, and an increase in labour availability should lower the opportunity cost of labour. However, that reduction is across the board, and, therefore, the relationship between fuelwood source and household size must be empirically examined, although the relaxation of the labour constraint should increase the probability of the use of multiple sources. Similarly, the gender, and education of the household head are included as proxies for the cost of the household head's labour, while the age of the household head provides an indication of ties to the land; specifically, older household heads have had more time to develop their own private forests, which could increase the probability of using private forests. Increases in wage costs, as was the case with labour supply, affects labour allocation across the board, such that the relationship between gender and education remains an empirical question. Education, though, is also expected to proxy for the ability to understand the structures associated with forestry institutions and the potential benefits of land certification, and, therefore, it is expected that education is associated with greater use of private sources of fuelwood and less use of open access sources.

The remaining variables in the empirical model include a regional dummy, to uncover regional agro-ecological differences in opportunity costs, a dummy for access to credit, a dummy representing the availability of newer cooking technologies, a land certification dummy and community forestry institutional perceptions. As noted above, land certification is expected to lower the opportunity cost of private forestry relative to the other fuelwood 
sources. Similarly, institutional perceptions are likely to differ by household type, such that households with community forestry access find community forests preferable to other sources, while households without access prefer other sources. It is also likely that the efficient use of biomass, through improved cook stoves, affects the demand for fuelwood, although the effect is for all sources, and, therefore, the relationship between new cook stoves and fuelwood source is not known a priori. Similarly, access to credit denotes the household's ability to immediately borrow money from any source (for example, from banks, microcredit institutions, friends, private lenders, or other sources), and, therefore, is assumed to account for attachment to the market, as well as access to collateral, potentially reducing the costs of both fuelwood market purchase and private fuelwood production.

In terms of the institutional variables, villagers' perceptions about the use and management of natural resources, such as forests, grazing land, and water were gathered during the field survey. Specifically, households were asked to rate their perceptions regarding forestry rules and regulations to four different statements on a five-point scale. Institutional response A refers to any system that might be in place to control fuelwood collection from communal lands. Institutional response B refers to limitations that might be placed on fuelwood collected from communal lands. Institutional response $\mathrm{C}$ concerns whether or not kebele officials monitor the people and products being removed from communal lands. Finally, institutional response $\mathrm{D}$ is concerned with penalty structures that might be in place for dealing with the violation of collection rules. Using these responses, categorical dummy variables related to perceptions - strongly disagree, disagree, neutral, agree and strongly agree - were created. Each response was considered in the analysis, although only two are reported in this analysis, Response A and D. Analyses of Responses B and C are available upon request; no significant institutional effects were uncovered for Reponses B or C. In 
addition, an index was constructed from this series of questions. The responses were aggregated, allowing us to create an average response, as well as an index. The index is based on a categorization of the average, either relatively strong, if the average is greater than or equal to three, or relatively weak, if the average is below three. Principal Components Analysis was also considered; however, due to the fact that there are only four different questions, it was determined that separate categorical variables could be accommodated, instead. Deininger et al. (2009) used the same data to assess the effects of a low-cost land registration program in Ethiopia, finding that these institutions increased land-related investments. In our analysis, we use the data to determine whether or not the institutions affect the opportunity costs, and thus the choice of fuelwood collection source.

\subsection{Descriptive statistics}

In the areas in which data were collected, there are a number of different places fuelwood can be gathered or collected. Although the majority of households accessed only one location, there were households that accessed more than one. Therefore, in addition to open access forests, community forests, private forests or market sources, we included multiple sources as a collection option. Primarily, these are households that used two sources, although a small number of households access more than two sources (only $0.2 \%$ of the sampled households).

Table 1: The Proportion of Households by Fuelwood Collection Source

\begin{tabular}{lcc}
\hline Source & Mean & SD \\
\hline \hline Private Forest & 0.723 & 0.45 \\
Community Forest & 0.077 & 0.27 \\
Open Access Forest & 0.073 & 0.26 \\
Market Source & 0.086 & 0.28 \\
Multiple Sources & 0.041 & 0.20 \\
\hline
\end{tabular}

The source choices, as a proportion of households, are noted in Table 1. The majority of the households $(72.3 \%)$ collect their fuelwood from private sources, while $7.7 \%$ of the sampled households collect from community forests and $8.6 \%$ of the sampled households collect from 
Table 2. Descriptive Statistics by Fuelwood Collection Source

\begin{tabular}{|c|c|c|c|c|c|}
\hline VARIABLES & Private & Community & Market & Open Access & Multiple Sources \\
\hline \multirow[t]{2}{*}{ In(age hh head) } & 3.9183 & 3.8490 & 3.7369 & 3.8745 & 3.8373 \\
\hline & (0.0105) & (0.0309) & $(0.0392)$ & $(0.0340)$ & $(0.0419)$ \\
\hline \multirow[t]{2}{*}{ Male hh head } & 0.8650 & 0.8190 & 0.8113 & 0.8105 & 0.8846 \\
\hline & $(0.0127)$ & $(0.0378)$ & $(0.0543)$ & $(0.0404)$ & $(0.0447)$ \\
\hline \multirow{2}{*}{ Educhh head } & 0.5014 & 0.4286 & 0.4151 & 0.3579 & 0.4808 \\
\hline & $(0.0186)$ & $(0.0485)$ & $(0.0683)$ & $(0.0494)$ & $(0.0700)$ \\
\hline \multirow[t]{2}{*}{ In(hh size) } & 1.8768 & 1.8238 & 1.6850 & 1.8169 & 1.9547 \\
\hline & $(0.0136)$ & $(0.0410)$ & $(0.0598)$ & $(0.0448)$ & $(0.0422)$ \\
\hline \multirow[t]{2}{*}{ Credit Access } & 0.8512 & 0.9238 & 0.8868 & 0.8632 & 0.9038 \\
\hline & $(0.0132)$ & $(0.0260)$ & $(0.0439)$ & $(0.0354)$ & $(0.0413)$ \\
\hline \multirow[t]{2}{*}{ New Stove } & 0.7934 & 0.8000 & 0.7925 & 0.6421 & 0.6346 \\
\hline & $(0.0150)$ & $(0.0392)$ & $(0.0562)$ & (0.0494) & $(0.0674)$ \\
\hline \multirow[t]{2}{*}{ Land Certificate } & 0.7755 & 0.8000 & 0.5849 & 0.5895 & 0.8462 \\
\hline & $(0.0155)$ & $(0.0392)$ & $(0.0683)$ & $(0.0507)$ & $(0.0505)$ \\
\hline \multirow[t]{2}{*}{ East Gojam } & 0.6074 & 0.7810 & 0.7547 & 0.6000 & 0.7115 \\
\hline & $(0.0181)$ & $(0.0406)$ & $(0.0597)$ & $(0.0505)$ & $(0.0634)$ \\
\hline \multirow{2}{*}{ InstAvg $>=3$} & 0.3471 & 0.2381 & 0.4151 & 0.4737 & 0.4231 \\
\hline & $(0.0177)$ & $(0.0418)$ & $(0.0683)$ & $(0.0515)$ & $(0.0692)$ \\
\hline \multirow[t]{2}{*}{ Institution A } & 2.5758 & 2.5714 & 3.2642 & 3.1895 & 2.5000 \\
\hline & $(0.0597)$ & $(0.1500)$ & $(0.2089)$ & $(0.1579)$ & $(0.2338)$ \\
\hline \multirow[t]{2}{*}{ Institution B } & 3.8251 & 3.7524 & 4.1321 & 3.7895 & 4.0192 \\
\hline & (0.0499) & $(0.1324)$ & $(0.1661)$ & (0.1379) & $(0.1912)$ \\
\hline \multirow[t]{2}{*}{ Institution C } & 2.7176 & 2.8095 & 2.8679 & 2.9474 & 2.6923 \\
\hline & $(0.0553)$ & $(0.1361)$ & $(0.1925)$ & $(0.1600)$ & $(0.2065)$ \\
\hline \multirow[t]{2}{*}{ Institution D } & 2.5344 & 2.8000 & 3.0189 & 3.2000 & 2.6154 \\
\hline & $(0.0594)$ & $(0.1473)$ & $(0.2262)$ & $(0.1643)$ & $(0.2365)$ \\
\hline \multirow[t]{2}{*}{ Inst Average } & 2.9132 & 2.9833 & 3.3208 & 3.2816 & 2.9567 \\
\hline & $(0.0387)$ & $(0.1026)$ & $(0.1418)$ & $(0.1221)$ & $(0.1501)$ \\
\hline \multirow[t]{2}{*}{$\ln (\mathrm{ha})$} & 0.2556 & 0.2923 & -0.2009 & -0.0591 & 0.3062 \\
\hline & $(0.0230)$ & $(0.0677)$ & $(0.0778)$ & $(0.0618)$ & (0.0935) \\
\hline \multirow[t]{2}{*}{$\ln (T L U)$} & 1.2344 & 1.0735 & 0.2947 & 0.7610 & 1.0070 \\
\hline & $(0.0377)$ & $(0.1020)$ & $(0.2148)$ & $(0.1405)$ & $(0.1501)$ \\
\hline \multirow[t]{2}{*}{ In(dist to town) } & 0.0492 & -0.0046 & -0.1697 & 0.3707 & 0.1262 \\
\hline & $(0.0334)$ & $(0.0683)$ & (0.1510) & (0.0798) & $(0.1134)$ \\
\hline \multirow[t]{2}{*}{ In(dist to forest) } & 0.6191 & 0.5149 & 0.7922 & 0.8294 & 0.5664 \\
\hline & $(0.0293)$ & $(0.0587)$ & $(0.1126)$ & $(0.0633)$ & (0.0838) \\
\hline Observations & 726 & 105 & 53 & 95 & 52 \\
\hline
\end{tabular}

Source: Data collected in Amhara Region of Ethiopia. Data presented as means, standard errors in parentheses.

open access (OA) areas. Furthermore, some households satisfy their fuelwood demand from the market (7.3\%). As should be expected, most of the households buying fuelwood from the market are those with minimal land holdings, as those households are unable to both plant trees and grow crops for their livelihood (Table 2). The remaining summary statistics for the participating households are presented in Table 2, by source of fuelwood. From Table 2, it can be inferred, through the calculation of $95 \%$ confidence intervals - the estimated mean 
$\pm 1.96 \times$ the estimated standard error -that many of the characteristics of the independent variables vary by collection source.

Table 3. Land Certification Marginal Effects

\begin{tabular}{|c|c|c|c|c|c|}
\hline VARIABLES & Private & Community & Market & Open Access & Multiple Sources \\
\hline \multicolumn{6}{|c|}{ Model I - Dummy for Institutional Average } \\
\hline \multirow[t]{2}{*}{ Land Certificate } & 0.0006 & 0.0273 & -0.0008 & $-0.0542 * *$ & $0.0271 *$ \\
\hline & $(0.0376)$ & $(0.0240)$ & $(0.0111)$ & $(0.0257)$ & (0.0139) \\
\hline \multirow[t]{2}{*}{ In(hectares) } & $0.0577^{* *}$ & 0.0066 & $-0.0260 * * *$ & $-0.0434 * * *$ & 0.0052 \\
\hline & $(0.0260)$ & $(0.0186)$ & $(0.0083)$ & (0.0139) & $(0.0121)$ \\
\hline \multicolumn{6}{|c|}{ Model II - Institutional Average } \\
\hline \multirow[t]{2}{*}{ Land Certificate } & -0.0119 & 0.0318 & 0.0003 & $-0.0498 * *$ & $0.0295^{* *}$ \\
\hline & $(0.0370)$ & $(0.0236)$ & $(0.0107)$ & $(0.0248)$ & $(0.0136)$ \\
\hline \multirow[t]{2}{*}{ In(hectares) } & $0.0561^{* *}$ & 0.0066 & $-0.0259 * * *$ & $-0.0418 * * *$ & 0.0051 \\
\hline & $(0.0259)$ & $(0.0187)$ & $(0.0081)$ & $(0.0136)$ & $(0.0122)$ \\
\hline \multicolumn{6}{|c|}{ Model III - Institution Response A } \\
\hline \multirow[t]{2}{*}{ Land Certificate } & -0.0136 & 0.0319 & -0.0017 & $-0.0435^{*}$ & $0.0269 * *$ \\
\hline & $(0.0352)$ & $(0.0226)$ & $(0.0118)$ & $(0.0228)$ & $(0.0130)$ \\
\hline \multirow[t]{2}{*}{ In(hectares) } & $0.0447^{*}$ & 0.0083 & $-0.0223 * * *$ & $-0.0363 * * *$ & 0.0056 \\
\hline & $(0.0252)$ & $(0.0182)$ & $(0.0085)$ & $(0.0131)$ & $(0.0115)$ \\
\hline \multicolumn{6}{|c|}{ Model IV - Institution Response D } \\
\hline \multirow[t]{2}{*}{ Land Certificate } & -0.0178 & $0.0398 *$ & -0.0053 & $-0.0420 *$ & $0.0254^{* *}$ \\
\hline & $(0.0357)$ & $(0.0216)$ & $(0.0123)$ & $(0.0238)$ & $(0.0125)$ \\
\hline \multirow[t]{2}{*}{ In(hectares) } & $0.0669 * * *$ & 0.0044 & $-0.0282 * * *$ & $-0.0467 * * *$ & 0.0037 \\
\hline & $(0.0255)$ & $(0.0183)$ & $(0.0085)$ & $(0.0137)$ & $(0.0110)$ \\
\hline \multicolumn{6}{|c|}{ Model V - Institution Response A and D } \\
\hline \multirow[t]{2}{*}{ Land Certificate } & -0.0176 & 0.0342 & -0.0014 & $-0.0397^{*}$ & $0.0244^{*}$ \\
\hline & $(0.0357)$ & $(0.0230)$ & $(0.0113)$ & $(0.0228)$ & $(0.0126)$ \\
\hline \multirow[t]{2}{*}{ In(hectares) } & $0.0600 * *$ & 0.0052 & $-0.0252 * * *$ & $-0.0428 * * *$ & 0.0028 \\
\hline & $(0.0255)$ & (0.0187) & $(0.0083)$ & $(0.0130)$ & $(0.0110)$ \\
\hline
\end{tabular}

Source: Marginal Effects from Multinomial Logit Estimates. Standard Errors in Parentheses.

$* * *$ Significant at $0.01, * *$ Significant at $0.05, *$ Significant at 0.1 .

\section{RESULTS OF ECONOMETRIC ANALYSIS}

The empirical results of the multinomial logit models are presented in Tables 3-5. As there are many different measures of institutional perceptions, the different panels in Tables 3 and 4 provide an indication of the robustness of results to those different measures. Table 3 
Table 4. Institutional Marginal Effects

\begin{tabular}{|c|c|c|c|c|c|}
\hline VARIABLES & Private & Community & Market & Open Access & Multiple Sources \\
\hline \multicolumn{6}{|c|}{ Model I - Dummy for Institution Average } \\
\hline \multirow[t]{2}{*}{ Institute Average > 3} & -0.0225 & -0.0155 & $0.0176^{*}$ & $0.0294^{*}$ & -0.0091 \\
\hline & $(0.0274)$ & $(0.0191)$ & $(0.0097)$ & $(0.0154)$ & $(0.0127)$ \\
\hline \multicolumn{6}{|c|}{ Model II - Institutional Average } \\
\hline \multirow[t]{2}{*}{ Institute Average } & $-0.0314 * *$ & 0.0018 & $0.0093 * *$ & $0.0190 * * *$ & 0.0013 \\
\hline & $(0.0128)$ & $(0.0092)$ & $(0.0043)$ & $(0.0069)$ & $(0.0060)$ \\
\hline \multicolumn{6}{|c|}{ Model III - Institution Response A } \\
\hline \multirow[t]{2}{*}{ A: Disagree } & $-0.0760 *$ & 0.0107 & 0.0034 & $0.0669 *$ & -0.0050 \\
\hline & $(0.0450)$ & $(0.0280)$ & $(0.0175)$ & $(0.0352)$ & (0.0159) \\
\hline \multirow[t]{2}{*}{ A: Neutral } & $-0.2063 * * *$ & $0.0977^{*}$ & 0.0181 & 0.1026 & -0.0120 \\
\hline & $(0.0773)$ & $(0.0577)$ & $(0.0292)$ & $(0.0650)$ & $(0.0230)$ \\
\hline \multirow[t]{2}{*}{ A: Agree } & $-0.0744^{*}$ & -0.0206 & $0.0365^{*}$ & $0.0800 * *$ & -0.0215 \\
\hline & $(0.0412)$ & $(0.0231)$ & $(0.0198)$ & $(0.0319)$ & $(0.0131)$ \\
\hline \multirow[t]{2}{*}{ A: Strongly Agree } & $-0.1190 * * *$ & -0.0148 & 0.0228 & $0.1008 * * *$ & 0.0102 \\
\hline & $(0.0434)$ & $(0.0247)$ & $(0.0193)$ & $(0.0349)$ & $(0.0174)$ \\
\hline \multicolumn{6}{|c|}{ Model IV - Institution Response D } \\
\hline \multirow[t]{2}{*}{ D: Disagree } & $-0.0882^{*}$ & 0.0412 & -0.0057 & 0.0402 & 0.0124 \\
\hline & $(0.0512)$ & $(0.0384)$ & $(0.0142)$ & $(0.0353)$ & $(0.0216)$ \\
\hline \multirow[t]{2}{*}{ D: Neutral } & $-0.1235^{* *}$ & $0.1176^{* *}$ & 0.0008 & 0.0423 & $-0.0372 * * *$ \\
\hline & $(0.0584)$ & $(0.0502)$ & $(0.0174)$ & $(0.0395)$ & $(0.0117)$ \\
\hline \multirow[t]{2}{*}{ D: Agree } & $-0.1030 * *$ & 0.0506 & 0.0054 & $0.0517^{*}$ & -0.0047 \\
\hline & $(0.0427)$ & $(0.0323)$ & $(0.0140)$ & $(0.0295)$ & $(0.0149)$ \\
\hline \multirow[t]{2}{*}{ D: Strongly Agree } & $-0.1521 * * *$ & 0.0167 & 0.0191 & $0.1089 * * *$ & 0.0075 \\
\hline & $(0.0441)$ & $(0.0296)$ & $(0.0167)$ & $(0.0351)$ & $(0.0162)$ \\
\hline \multicolumn{6}{|c|}{ Model V - Institution Response A and D } \\
\hline \multirow[t]{2}{*}{ A: Disagree } & -0.0304 & -0.0102 & -0.0002 & 0.0471 & -0.0062 \\
\hline & $(0.0452)$ & $(0.0270)$ & $(0.0170)$ & (0.0334) & (0.0161) \\
\hline \multirow[t]{2}{*}{ A: Neutral } & $-0.1530 * *$ & 0.0575 & 0.0181 & 0.0832 & -0.0058 \\
\hline & (0.0777) & (0.0517) & $(0.0293)$ & (0.0611) & (0.0257) \\
\hline \multirow[t]{2}{*}{ A: Agree } & -0.0360 & $-0.0382 *$ & 0.0305 & $0.0666 * *$ & $-0.0229 *$ \\
\hline & $(0.0427)$ & (0.0227) & (0.0199) & (0.0319) & (0.0131) \\
\hline \multirow[t]{2}{*}{ A: Strongly Agree } & -0.0575 & -0.0219 & 0.0138 & $0.0558 *$ & 0.0098 \\
\hline & $(0.0443)$ & $(0.0260)$ & $(0.0178)$ & $(0.0316)$ & (0.0187) \\
\hline \multirow[t]{2}{*}{ D: Disagree } & -0.0771 & 0.0424 & -0.0043 & 0.0216 & 0.0173 \\
\hline & (0.0530) & (0.0417) & $(0.0144)$ & (0.0303) & (0.0249) \\
\hline \multirow[t]{2}{*}{ D: Neutral } & -0.0968 & $0.1209 * *$ & -0.0039 & 0.0146 & $-0.0348 * * *$ \\
\hline & (0.0601) & (0.0549) & $(0.0153)$ & $(0.0310)$ & (0.0129) \\
\hline \multirow[t]{2}{*}{ D: Agree } & $-0.0920 * *$ & $0.0714^{*}$ & -0.0011 & 0.0198 & 0.0019 \\
\hline & $(0.0455)$ & $(0.0382)$ & $(0.0126)$ & $(0.0243)$ & $(0.0173)$ \\
\hline \multirow[t]{2}{*}{ D: Strongly Agree } & $-0.1186 * *$ & 0.0313 & 0.0163 & $0.0650 * *$ & 0.0061 \\
\hline & $(0.0468)$ & $(0.0348)$ & $(0.0171)$ & (0.0319) & $(0.0176)$ \\
\hline
\end{tabular}

Source: Marginal Effects from Multinomial Logit Estimates. Standard Errors in Parentheses.

$* * *$ Significant at $0.01, * *$ Significant at $0.05, *$ Significant at 0.1 . 
Table 5. Other Marginal Effects (Model I)

\begin{tabular}{|c|c|c|c|c|c|}
\hline VARIABLES & Private & Community & Market & Open Access & Multiple Sources \\
\hline \multirow[t]{2}{*}{ In(age of hh head) } & $0.1605^{* * *}$ & -0.0501 & $-0.0435^{* * *}$ & -0.0236 & $-0.0432 * *$ \\
\hline & $(0.0475)$ & $(0.0339)$ & $(0.0156)$ & $(0.0242)$ & $(0.0206)$ \\
\hline \multirow[t]{2}{*}{ Male } & -0.0054 & -0.0150 & 0.0058 & 0.0067 & 0.0079 \\
\hline & (0.0399) & $(0.0303)$ & $(0.0113)$ & $(0.0184)$ & $(0.0166)$ \\
\hline \multirow[t]{2}{*}{ Education } & $0.0845^{* * *}$ & -0.0262 & -0.0100 & $-0.0368 * *$ & -0.0114 \\
\hline & $(0.0277)$ & $(0.0200)$ & $(0.0095)$ & $(0.0150)$ & $(0.0119)$ \\
\hline \multirow[t]{2}{*}{ In(hh size) } & -0.0404 & -0.0217 & -0.0146 & 0.0249 & $0.0518^{* * *}$ \\
\hline & $(0.0399)$ & $(0.0279)$ & $(0.0120)$ & $(0.0210)$ & $(0.0194)$ \\
\hline \multirow[t]{2}{*}{ Credit Access } & $-0.0737^{* *}$ & $0.0602^{* * *}$ & 0.0103 & -0.0064 & 0.0096 \\
\hline & $(0.0345)$ & $(0.0203)$ & $(0.0111)$ & $(0.0218)$ & $(0.0158)$ \\
\hline \multirow[t]{2}{*}{ New Cook Stove } & $0.1003^{* * *}$ & 0.0030 & -0.0010 & $-0.0607^{* * *}$ & $-0.0416^{* *}$ \\
\hline & $(0.0352)$ & $(0.0230)$ & $(0.0112)$ & $(0.0223)$ & $(0.0187)$ \\
\hline \multirow[t]{2}{*}{ East Gojam } & $-0.1192^{* * *}$ & $0.0744^{* * *}$ & $0.0289 * * *$ & -0.0075 & $0.0235^{* *}$ \\
\hline & $(0.0292)$ & $(0.0200)$ & $(0.0101)$ & $(0.0169)$ & $(0.0119)$ \\
\hline \multirow[t]{2}{*}{$\ln (T L U)$} & $0.0506^{* * *}$ & -0.0079 & $-0.0126^{* * *}$ & $-0.0152^{* *}$ & $-0.0150 * * *$ \\
\hline & (0.0134) & $(0.0095)$ & $(0.0037)$ & $(0.0063)$ & $(0.0052)$ \\
\hline \multirow[t]{2}{*}{ In(dist to town) } & -0.0142 & $-0.0185^{*}$ & $-0.0119 * *$ & $0.0401 * * *$ & 0.0045 \\
\hline & $(0.0162)$ & $(0.0109)$ & $(0.0047)$ & $(0.0104)$ & $(0.0070)$ \\
\hline \multirow[t]{2}{*}{ In(dist to forest) } & -0.0139 & 0.0017 & 0.0089 & 0.0036 & -0.0003 \\
\hline & $(0.0208)$ & $(0.0155)$ & $(0.0065)$ & $(0.0110)$ & $(0.0088)$ \\
\hline
\end{tabular}

Source: Marginal Effects from Multinomial Logit Estimates. Standard Errors in Parentheses.

$* * *$ Significant at $0.01, * *$ Significant at $0.05, *$ Significant at 0.1 .

contains the land security marginal effects, while Table 4 contains the institutional marginal effects. Finally, Table 5 contains the marginal effects related to the other variables included in the analysis. Complete marginal effects estimates from the multinomial logit models are presented in Appendix Tables A1 through A5, available in Damte and Koch (2011).

\subsection{Land certification and land holdings}

Contrary to our expectation, tenure security is not estimated to significantly reduce the cost of fuelwood collection from own sources. One possible explanation for the observed limited effect is that private sources require an initial and sustained investment in forests that has not, yet, led to significantly increased stocks that can be used by households. Poverty and high discount rates (not considered in this paper) might be more important factors than tenure 
security (land certification) in affecting farmer's decision regarding resource use from different sources. For example, high levels of poverty could be associated with high discount rates, and high discount rates would lead to low levels of investment. Regardless, additional empirical research on the role of land certification, farmers' long-term investment decisions and household's choices for forest product sources may be required to supplement these findings.

The certification results also support a slightly different hypothesis, that land certification has not impacted investments enough to allow households to rely solely on their own sources. According to the results in Table 3, tenure security does increase the probability that households make use of multiple fuelwood sources, with the estimated marginal effect ranging from $2.4 \%$ to $3 \%$. Although land security has not been found to have a significant impact on the costs of producing fuelwood from private sources, it has significantly increased the cost of collecting fuelwood from open access forests, thus lowering the probability of collection from these sources between $4 \%$ and $5.4 \%$, possibly because land certification has reduced the availability of open access forests. This finding suggests a positive effect for land tenure security, especially in terms of forest degradation. According to this analysis, tenure security significantly reduces the pressure placed on open access forests.

As expected, land holdings are an important determinant of fuelwood source choice. Increased land holdings reduce the opportunity cost of private fuelwood production, allowing for substitution away from other sources. Our analysis suggests that a $1 \%$ increase in land holdings results in a 0.045 to 0.067 point in the probability of private production, that is offset by an approximate 0.025 point reduction in the probability of purchasing firewood and an approximate 0.045 point reduction in the probability of collecting fuelwood from open 
access forests. Heltberg et al. (2000) draw similar conclusions in their analysis conducted in India - larger landowners collect less fuelwood from the commons and produce more fuelwood privately. Similarly, Cooke et al. (2008) argue that households with little or no land are less able to produce fuelwood themselves.

\subsection{Community forestry institutions}

With respect to community forestry institutions, Table 4, the results are less clear-cut, although that may not be entirely surprising, given the previous discussion. Our expectation was that strong forestry institutions would increase community forest productivity and the probability of collection from community forests for those with community forestry access, but increase opportunity costs and reduce the probability of collection for those without access. There is strong evidence that community forestry institutions, strong or not, raise the cost of private fuelwood production, and reduce the probability that fuelwood is collected or produced privately. If the respondent feels that institutions are relatively stronger - the respondent does not strongly disagree with the statement, the average response is higher or the average response leans towards agreement - the probability that the household collects from their own sources is lowered. For example, in Model III - institutional Response A, a neutral response is associated with a $20 \%$ reduction in the probability of collection from own sources, while strong agreement is associated with a $12 \%$ reduction.

There is also consistent empirical evidence that community forestry institutions lead to substitution towards open access forests, a result that is theoretically consistent, especially for households without access to community forests. Relatively strong institutions limit the ability of non-member households to make use of the community forests, resulting in more use of less institutional structures, such as open access forests. With respect to fuelwood purchases, which also could be expected to increase in the face of stronger community 
forestry institutions, only limited evidence is available in support of that hypothesis. Market participation probabilities are generally higher for both the average institute and the institutional dummy, but not related to specific institutional responses. Finally, some evidence is uncovered suggesting that stronger institutions reduce the probability that households make use of multiple sources.

The effect of institutions on community forest collection activities is the most difficult to generalize. Neutral responses with respect to institutional response A and institutional response $\mathrm{D}$ are associated with increased probabilities of community forest collection participation, and the marginal effect is approximately $10 \%$ in both cases. However, when including institutions $\mathrm{A}$ and $\mathrm{D}$ simultaneously, neutral responses and agreements to institution D are associated with a $12.1 \%$ and $7.1 \%$, respectively, increase in the probability of community forest collection, while agreement with institution $\mathrm{A}$ is associated with a $3.8 \%$ decrease in community forest collection probabilities.

The creation of community forests is expected to create insiders and outsiders, those with access to the community forests and those without. Therefore, it is not surprising to find substitution between community forests and other fuelwood options, and it is not surprising that stronger institutions lead to increased substitution for the outsiders and increased collection from the insiders. In that sense, the increased reliance on open access forests and fuelwood markets was expected. Taken further, the increased collection from is capable of explaining the negative relationship between institutional strength and reduced collection from own and multiple sources. The increased productivity of community forests for insiders would increase the relative cost of collection from own and multiple sources. In terms of policy, the unintended consequences of an expansion of community forests, in tandem with 
strong local-level institutional control, will not help reduce the depletion and degradation of forests and forest products, because it diverts households away from community forests, which can be properly managed, towards open access forests. On the other hand, if all open access forests are turned into community forests, and those community forests are properly managed, our results imply that it is possible that forest degradation can be alleviated.

\subsection{Other determinants of fuelwood collection source}

The remainder of the estimation results examine other potential relative cost-drivers of fuel source choices. Initially, it was expected that livestock holdings would compete with fuelwood production activities on private land, and thus reduce the probability of private production, although our results do not support that hypothesis. Other studies, such as that by Edmunds (2002), have included livestock holdings amongst other measures of wealth. Regardless of the measure of wealth used in previous studies, each finds that most poor households cannot afford to buy fuelwood from the market. Therefore, it is reasonable to expect poor households to depend more on forests owned by government (de facto open access) in order to satisfy their energy requirements. In that sense, the results are more in line with the view that livestock ownership is a wealth measure, rather than a competitor for land use. Specifically, a $1 \%$ (TLU) increase in livestock ownership is associated with a significant 0.051 point increase in the probability of collecting fuelwood from private sources, but was associated with a significant 0.015 point reduction in the probability of collecting fuelwood from open access forests and multiple sources, as well as a 0.013 point reduction in the probability of market purchases.

Two additional measures, credit opportunities and access to improved biomass cook stoves, were included in the analysis, although their influence on the choices examined here could 
not be determined from the theoretical model. However, if one views improved cook stoves as an asset then one would expect similarity between the cook stove estimates and the livestock holdings estimates. In fact, that is what is observed. Ownership of these stoves is associated with an increased probability of privately sourced fuel (10\%), but is associated with a reduced probability of openly sourced fuel (5.3\%) and multiple sources of fuelwood (4.2\%). Credit opportunities, on the other hand, do not have the same effect as other sources of wealth, possibly because they signal a current wealth shortage, although they might also signal borrowing for investment purposes. We find that credit access reduces the probability of using private sources by $7.4 \%$, but raises the probability of accessing community forests for fuelwood by $6 \%$.

A number of location-specific variables, such as the household's distance to the nearest town and distance to the nearest forest, as well as a region-specific dummy variable were also included in the analysis to uncover other costs and differences in fuelwood collection, production and purchasing activities. As most markets are located in or near towns, it is not surprising that increases in the distance to town, measured in walking time hours, which mimics an increase in the opportunity cost of fuelwood purchase, reduces the probability of fuelwood purchase from the market; a $1 \%$ increase in the distance reduces the probability by 0.012 points. Similarly, households located farther from town have a lower probability of collecting fuelwood from community forests ( $1.9 \%$ per $100 \%$ increase). We also find that the distance from town raises the probability of fuel collection from open access forests; a $100 \%$ increase in the distance increases the probability by 4\%. Surprisingly, the household's distance from the nearest forest has no impact on fuelwood source. Overall, these results provide little support to other studies (e.g., Heltberg et al., 2000) that people tend to substitute fuelwood from forests with private fuels as distance to forests increase. In terms of the 
regional effect, it was significantly related to all sources, except for open access forests. We find that households in East Gojam are less dependent on private sources (11.9\%), but more dependent on community forests $(7.4 \%)$, market purchases $(2.9 \%)$ and multiple sources (2.4\%), compared to households in the South Wollo region.

Finally, the age, education and gender of the household head, as well as household size, were included to proxy for the costs of labour at the household level, as well as the ability of the household to understand the community forestry institutions, conservation and potential land certification benefits. The age of the household head increases the probability that the household collects from own sources, and lowers the probability that households make use of either the market or multiple collection sources, suggesting that households headed by older individuals have relatively lower costs of private forest production, possibly because they have been on their land longer and invested longer in the land. The education of the household head also raises the probability that households collect from their own sources (by $8.5 \%$ ), but lowers the probability that households collect from open access forests (by $3.7 \%$ ), suggesting that education lowers the cost of private collection relative to open access collection. The education result is consistent with the hypothesis that education improves the understanding of conservation; if educated household heads are more aware of the importance of forest conservation and its use in maintaining soil fertility and mitigating climate change effects, they would be more likely to invest in their own land, produce from that land, and reduce their dependence on open access forests. In terms of household size, contrary to Jumbe and Angelsen (2011), we find that household size only impacts, positively, the probability of collection from multiple sources, probably because larger households have lower access opportunity costs, generally, and find it easier to take advantage of more collection opportunities. 


\section{CONCLUSION}

In this paper, we have examined the determinants of rural households' costs of collecting, producing or purchasing fuelwood using a discrete choice model, underpinned by a simple cost minimization problem tied to a variant of the random utility framework. The model has been employed to examine whether socioeconomic and environmental factors affect the costs of accessing fuelwood, and, thus, rural Ethiopian household choices, with a specific emphasis on land security and institutional factors related to the community forestry program that is available in the region. The analysis was undertaken using data collected from the East Gojam and South Wollo zones of the Amhara region of Ethiopia.

The primary purpose of the analysis was to consider the importance of local-level institutions and land certification on these choices, in order to provide information to policymakers, since the current government of Ethiopia and other organizations working on natural resource conservation are promoting the transfer of land and forests to local people. In terms of the analysis, institutions do play a role in household choices, although not completely as expected. Better institutions are associated with a reduced probability of collecting fuelwood from private sources and multiple sources, while raising the probability of collecting fuelwood from open access forests and community forests. With respect to policy, the results are positive, in the sense that community forestry use is increased under stronger institutions. Unfortunately, the results are also negative, in the sense that the propensity of fuelwood collection from open access forest resources also increases, in the face of better community forestry institutions. In other words, the main policy implication that can be gleaned from the results is that there is a need to bring additional open access forests under the management of the community and increase local awareness related to the rules associated with forestry management, as well as benefits of improved conservation. However, additional research is 
needed to provide better understanding related to the impact of improved community forestry institutions on private source fuelwood collection. As this research only focused on production and collection source, and not actual quantity produced, collected or consumed, there is scope to extend the analysis to examine the effect of land certification and forestry institutions on substitution at the level of production and consumption, similar to Mekonnen (1999).

Land certification, on the other hand, is associated with reduced collection probabilities in open access forests and increased collection probabilities for multiple sources for fuelwood collection. However, although the literature (Deiningeret al., 2009; Holden et al., 2009) suggests that land certification is responsible for increased investment in the land's productivity, through better soil conservation and the planting of trees, our results suggest that these investments have, as yet, not resulted in significantly increased use of private forests for fuelwood. The lack of significance is likely due to a long investment lag - it is unlikely that trees planted within the last few years have grown big enough for harvest however, in terms of policy, the reduced probability of collecting from open access forests is a positive result, suggesting that land certification should be furthered. Additional empirical research on the role of land certification, as well as farmers' investment and use decisions may be required to supplement these findings, especially in terms of understanding the impact of certification on private forestry development and use.

A number of additional implications can be developed from the analysis. Firstly, education is negatively correlated with the probability of fuelwood collection from open access forests, suggesting that improving education could lead to improved forest conservation by reducing the pressure on open access areas. The current extension system in Ethiopia may have a role 
to play in this regard, if the extension system can undertake useful education interventions related to forest management and conservation. Secondly, the choice of fuelwood source also varies between regions, suggesting that there is a need to consider regional variation when examining household choices. Thirdly, households with large landholdings and greater livestock ownership are more likely to collect fuelwood from their own private sources and are less likely to collect from either open access forests or purchase from the market. Regarding policy interventions related to forest conservation, especially in open access areas, they would be more likely to succeed, if the interventions are capable of targeting the poorer households in the region. Finally, distance matters. The probability of market purchase is increased when households are closer to town, suggesting that people will depend more on the market as urban communities become more accessible, e.g., as transport infrastructure improves. Similarly, the probability of collection from open access areas is increased for households located farther away from town. Therefore, policies designed to increase the availability of fuelwood, or at least increase access to towns may help reduce fuelwood expenditures and environmental pressures on open access forests.

The results from this study can provide valuable insight for Ethiopia's current demand-side and supply-side strategies for addressing rural energy problems, especially policies related to forests and forest resource conservation, as well as halting, and hopefully reversing, the unsustainable use and exploitation of those resources. Future studies in this area are necessary, and can provide further information related to the long-term effect of land tenure security (land certification) on farmers' investment decisions, and the implication of these decisions on rural energy demand and forest degradation in the region. Although this study provides a number of meaningful insights with respect to forestry conservation and management, focusing on an application to rural Ethiopian households, it is likely that the 
results and policy implications can be generalized to other developing regions. Importantly, many developing regions have similar forestry structures, in that forests are owned by the government, and suffer from many of the same problems, such as forest degradation that is continuing (or even accelerating) on a pace that is likely to be unsustainable. Therefore, even though the analysis focuses on a very specific region of one country, the similarity of structures and problems suggests that there is scope for developing or extending these policies in other similar countries.

\section{ACKNOWLEDGEMENT}

The authors would like to thank Addis Ababa University, the University of Gothenburg, and the Swedish International Development Cooperation Agency and the Swedish Agency for Research Cooperation for their help in accessing the data used for the analysis. Furthermore, the authors would like to thank Economic Research Southern Africa for their financial support of this research. Finally, the authors would also like to thank anonymous reviewers associated with both Forest Policy and Economics and Economic Research Southern Africa for the comments made on previous drafts. Those comments have greatly improved this research and its presentation. Any remaining errors are the sole responsibility of the authors. 


\section{REFERENCES}

Agrawal, A. 2000. Sustainability of the commons. Paper presented at the " 8 th Biennial Conference of the International Association for the Study of Common Property," Bloomington, IN, USA, May 30-June 4, 2000.

Agrawal, A. 2001. Common property institutions and sustainable governance of resources. World Development 29 (10): 1649-72.

Agrawal, A. Chatre, A., Hardin, R. 2008. Changing governance of the world's forests. Science 320: 1460-1462

Ben-Akiva, M., Bolduc, D. and Bradley, M. 1993. Estimation of travel choice models with randomly distributed values of time, Transportation Research Record 1413: 88-97.

Bluffstone, R., Boscolo, M. and Molina, R. 2008. Does better common property forest management promote behavioral change? On-farm tree planting in the Bolivian Andes. Environment and Development Economics 13: 137-70.

Central Statistical Agency (CSA). 2012. Ethiopian Welfare Monitoring Survey 2011: Summary Report, http://www.csa.gov.et/, accessed October 24, 2012.

Cooke, P., Hyde, W.F., and Köhlin, G. 2008. Fuelwood, forests and community management-evidence from household studies. Environment and Development Economics 13(1): 103-135.

Damte, A.B., and Koch, S.F. 2011. Property rights, institutions and source of fuelwood in rural Ethiopia. Economic Research Southern Africa: Working Paper No. 245.

Deininger, K., Ali, D.A., Holden, S., and Zevenbergen, J. 2008. Rural land certification in Ethiopia: Process, initial impact, and implications for other African countries. World Development 36(10): 1786-1812.

Deininger, K., Ali, D.A., and Alemu, T. 2009. Impacts of land certification on tenure security, investment, and land markets, EfD Discussion Paper 09-11, a joint 
publication of the Environment for Development Initiative and Resources for the Future (www.rff.org), Washington: RFF.

Edmunds, E. 2002. Government initiated community resource management and local resource extraction from Nepal's forests. Journal of Development Economics 68(1): 89-115.

FAO (Food and Agriculture Organization), 2010. Global Forest Resources Assessment 2010. Main report, FAO Forestry Paper 163. Rome: UNFAO.

Greene, W., 2003.Econometric Analysis, $5^{\text {th }}$ Edition. New York: Macmillan.

Hardin, G., 1968. The tragedy of the commons. Science 162(3859): 1243-1248.

Heltberg R., Arndt, A., and Sekhar, N.U. 2000. Fuelwood consumption and forest degradation: A household model for domestic energy consumption in rural India. Land Economics 76(2): 213-232.

Holden, S., Deininger, K., and Ghebru, H. 2009. Impacts of low-cost land certification on investment and productivity. American Journal of Agricultural Economics 91(2): $359-373$.

Jumbe, C.B.Land Angelsen, A. 2011. Modeling choice of fuelwood source among rural households in Malawi: A multinomial probit analysis. Energy Economics 33(5): 732738.

Linde-Rahr, M. 2003. Property rights and deforestation: The choice of fuelwood source in rural Vietnam. Land Economics 79(2): 217-234.

Mamo, G., E. Sjaastad, and Vedeld, P. 2006. Economic dependence on forest resources: A case from Dendi District, Ethiopia. Forest Policy and Economics 9(8): 916-927.

McFadden, D. 1973. Conditional logit analysis of qualitative choice behaviour, in: P. Zarembka (ed.), Frontiers in Econometrics, Academic Press, New York, S. 105-142.

McFadden, D. 1974. The measurement of urban travel demand. Journal of Public Economics 3(4): 303-28. 
Mekonen, A., and Bluffstone, R. 2007. Policies to increase forest cover in Ethiopia: Lessons from economics and international experience, in Bane, J., S. Nune, A. Mekonen and R.Bluffstone (Eds), Policies to increase forest cover in Ethiopia, Proceedings of Policy Workshop, Environmental Economics Policy Forum for Ethiopia, Ethiopian Development Research Institute, Addis Ababa, Ethiopia.

Mekonnen, A. 1999. Rural household biomass fuel production and consumption in Ethiopia: A case study. Journal of Forest Economics 5(1): 69-97.

Mekonen, A. 2009. Tenure security, resource endowments and tree growing: Evidence from the Amhara region of Ethiopia. Land Economics 85(2): 292-307.

Mekonnen, A., and Bluffstone, R. 2008. Is there a link between common property forest management and private tree growing? Evidence of behavioral effects from Highland Ethiopia. RFF Discussion Paper EfD 08-29, Washington, DC: Resources for the Future and Environment for Development.

Ministry of Agricultureand and Rural Development (MoARD). 2007. Forest Development, Conservation and Utilization, Policy and Strategy, Addis Ababa.

Ostrom, E. 1990. Governing the Commons: The Evolution of Institutions for Collective Action. New York: Cambridge University Press.

Train, K. 1998. Recreation demand models with taste differences over people. Land Economics 74: 230 -239. 